\title{
DESENVOLVIMENTO DE BEBIDA MISTA A BASE DE AIPIM, MANGA E
}

MEL

\author{
Jailma Custodio Ribeiro Santos ${ }^{1}$; Silvia Maria Almeida de Souza ${ }^{2}$; \\ Ernesto Acosta Martinez ${ }^{3}$ \\ 1. Bolsista PIBIC/CNPq, Graduanda em Engenharia de Alimentos, Universidade Estadual de Feira de Santana, e- \\ mail: jailma ribeiro30@hotmail.com \\ 2. Orientadora, Departamento de Tecnologia, Universidade Estadual de Feira de Santana, e-mail: \\ ss_almeida@yahoo.com.br \\ 3. Professor, Departamento de Tecnologia, Universidade Estadual de Feira de Santana, e-mail: \\ ernesto.amartinez@yahoo.com.br
}

PALAVRAS-CHAVE: novos produtos, antioxidante, energético.

\section{INTRODUÇÃO}

O aproveitamento de matérias primas gerados da agricultura familiar é apontado como uma possibilidade viável para a melhoria das condições econômicas e para a segurança alimentar da região semiárida, além disso, reforça a ideia de agregar valor a produtos processados. O desenvolvimento de novos produtos (DNP) contendo matérias primas obtidas no semiárido baiano como o aipim e manga é uma alternativa de uso sustentável para produção de um produto que pode ser consumido por uma gama de consumidores (SANTOS, et. al., 2017). Atrelado ao DNP novas formulações de bebida mista é uma alternativa que combina o habito do consumo de alimentos naturais, complementação de nutrientes fornecidos por ingredientes diferentes, e o consumo de bebidas não carbonatadas "prontas para beber" crescente no Brasil (ABREU, et al, 2011).

O Brasil e principalmente a região semiárida apresenta características especiais de flora e clima que, lhe conferem um potencial fabuloso para a atividade apícola, o cultivo de mandioca e a produção de manga. O mel apresenta uma composição complexa da qual fazem parte cerca de 180 componentes diferentes, constituído por frutose e glicose, apresentando também, outros carboidratos, água e diversos constituintes nos quais se incluem compostos fenólicos e flavonóides, minerais, enzimas, aminoácidos e vitaminas, além disso, apresenta compostos antioxidantes e pode ser utilizado como adoçante natural (SERRA, 201_). A mandioca é planta tolerante à seca e a solos de baixa fertilidade e pode ser cultivada durante todo o ano, sua classificação baseia-se no teor de ácido cianídrico, enquanto a mandioca-brava é rica neste componente a mandioca-mansa ou aipim tem as raízes com baixo teor de acido podendo ser consumido cozido ou assado (FILHO, 2013). Aipim é rico em teores de amido, que é a principal fonte de energia biológica na alimentação humana. No entanto o aipim possui valor agregado na forma in natura baixo, abrindo margem para $o$ uso em derivados. A manga contém vitaminas (A, C, E), flavonoides e outros nutrientes que conferem propriedades antioxidantes (GRANJA, et al, 2014), ou seja, a manga tem a função de potencializar a valor nutricional da bebida, além de ser responsável pela coloração e sabor da fruta. A Bahia apresenta 38,54 \% de manga cultivada do total da região nordestina, produção alta se comparada com os outros estados Nordestinos (SILVA; CORREIA, 2004), desta forma a disponibilidade da fruta e consequentemente da polpa industrial favorece a utilização para produção do novo produto.

Diante do exposto, a bebida à base de aipim, manga e mel, na forma de "pronto para beber" surge como uma alternativa de maximizar a produção e comercialização da 
matéria prima gerando maiores rendas para os agricultores familiares e fornecer segurança alimentar à comunidade já que a bebida mista poderá ser aplicada na merenda escolar da região e ser consumida por pessoas de qualquer faixa etária, por agregar valor nutricional e praticidade de consumo.

\section{MATERIAL E MÉTODOS OU METODOLOGIA}

Preparo da amostra: A polpa de manga comercial foi adquirida no comercio local levada ao Laboratório de Processamento Industrial de Alimentos/Labotec II/UEFS, onde foi higienizada e filtrada para a realização das analises físico-químicas. O aipim foi adquirido de agricultores familiares do município de Coração de Maria, levados ao Laboratório, citado acima, onde foi selecionado, escovado e lavado em água corrente, sanitizado com solução clorada (200 ppm) por 20 minutos, enxaguado com água potável e descascado. Em seguida, o aipim foi cozido por cerca de 40 minutos, após o cozimento foi resfriado em banho de gelo, drenado e posteriormente triturado em processador com o auxilio de 50\% de água destilada, com relação á massa total de aipim. Para a realização das analises físico químicas a amostra foi filtrada para eliminar as fibras e compostos que pudessem interferir nas analises, (SANTOS, et. al., 2017).

Analises físico-químicas: Foram realizadas as analises de sólidos solúveis ( ${ }^{\circ}$ Brix) por refratômetro; $\mathrm{pH}$ em pHmetro segundo o Instituto Adolfo Lutz (2008); açucares redutores, segundo a metodologia de Maldonade (2013); açucares totais por Dubois, et. al., (1956); acidez titulável e vitamina C segundo a metodologia do Instituto Adolfo Lutz (2008). Todas às analises foram realizadas em triplicata

Desenvolvimento da bebida: Os ensaios foram realizados segundo planejamento fatorial $2^{3}$, variando as concentrações de manga (75 a $100 \mathrm{~g}$ ), aipim $(10$ a 17,5g) e sacarose ( 0 a $11 \mathrm{~g})$ a quantidade de água foi fixada em $50 \mathrm{~g}$ e mel em 2,5 g. Todos os ingredientes, previamente processados ou adquiridos, foram adicionados no liquidificador para homogeneização. A bebida mista foi armazenada sob refrigeração.

Avaliação da estabilidade: Foram medidos o pH e sólidos solúveis ( ${ }^{\circ}$ Brix) das formulações após o processamento nos dias 0, 3 e 15, assim como a analise visual da bebida como forma de quantificar e qualificar a perda de nutrientes durante $o$ armazenamento.

\section{RESULTADOS E/OU DISCUSSÃO}

A etapa inicial da preparação da amostra para as análises físico-químicas foi discutida em (SANTOS, et al, 2017). As análises físico-químicas da manga e do aipim foram realizadas de modo a conhecer as propriedades que pudessem interferir nos resultados da bebida mista. A analise foi feita para as amostras de aipim colhido no período de setembro de 2016 e com as de manga adquiridas neste mesmo período. As analises físico-químicas da polpa comercial de manga e do aipim são mostradas na Tabela 1.

Tabela 1: Características físico-químicas do aipim cozido e da polpa de manga comercial.

\begin{tabular}{ccc}
\hline Parâmetros & Aipim cozido & $\begin{array}{c}\text { Polpa de manga } \\
\text { comercial }\end{array}$ \\
\hline $\mathrm{pH}$ & $6,12 \pm 0,01$ & $3,55 \pm 0,01$ \\
Sólidos solúveis $\left({ }^{\circ} \mathrm{Brix}\right)$ & $15,00 \pm 0,10$ & $12,00 \pm 0,09$ \\
Acidez total (Ácido cítrico, \%) & $0,048 \pm 0,003$ & $0,671 \pm 0,014$ \\
Vitamina C (mg/100g) & $8,437 \pm 0,472$ & $54,152 \pm 1,451$ \\
Açúcares redutores $(\mathrm{g} / 100 \mathrm{~g})$ & $3,032 \pm 0,018$ & $7,136 \pm 0,063$ \\
\hline
\end{tabular}




\begin{tabular}{ccc}
\hline Açúcares totais $(\mathrm{g} / 100 \mathrm{~g})$ & $7,638 \pm 0,220$ & $16,163 \pm 0,750$ \\
Açúcares não redutores $(\mathrm{g} / 100 \mathrm{~g})$ & $4,606 \pm 0,119$ & $9,027 \pm 0,407$ \\
Umidade $(\%)$ & $87,644 \pm 0,343$ & $71,523 \pm 0,526$ \\
\hline
\end{tabular}

A análise de umidade determina o teor de água livre na amostra, na bebida foi importante para definir a quantidade de água a ser adicionada na bebida para obter um líquido de baixa viscosidade.

As demais análises foram discutidas no resumo expandido apresentado no congresso Brasileiro de Higienistas de alimentos 2017 (SANTOS, et al, 2017).

O mel utilizado foi o mel de abelha africana e teve Sólidos solúveis ( ${ }^{\circ}$ Brix) de 80,0 e ph de 3,90. O valor de pH do mel alterna entre 3,4 e 6,1, com uma média de 3,9 (IURLINA; FRITZ, 2005). Segundo Ferreira (2012) o ${ }^{\circ}$ Brix da abelha multifloral é de $80,1 \pm 0,89$.

Foi realizado o planejamentos $2^{3}$ onde foi fixada a quantidade em massa de mel em $2,5 \mathrm{~g}$ e de água em $50 \mathrm{~g}$, a quantidade de açúcar em massa variou de 0 a $11 \mathrm{~g}$. A tabela 2 mostra a matriz do planejamento fatorial $2^{3}$

Tabela 2: Matriz do planejamento fatorial $2^{3}$ para avaliar os efeitos das concentrações de manga, aipim e açúcar na qualidade sensorial da bebida mista.

\section{Codificado}

\begin{tabular}{cccc} 
Formulação & Aipim & Manga & Açúcar \\
\hline 1 & $-1,00$ & $-1,00$ & $-1,00$ \\
2 & 1,00 & $-1,00$ & $-1,00$ \\
3 & $-1,00$ & 1,00 & $-1,00$ \\
4 & 1,00 & 1,00 & $-1,00$ \\
5 & $-1,00$ & $-1,00$ & 1,00 \\
6 & 1,00 & $-1,00$ & 1,00 \\
7 & $-1,00$ & 1,00 & 1,00 \\
8 & 1,00 & 1,00 & 1,00 \\
9 & 0,00 & 0,00 & 0,00 \\
10 & 0,00 & 0,00 & 0,00 \\
11 & 0,00 & 0,00 & 0,00 \\
\hline
\end{tabular}

Foram realizados 11 ensaios, incluindo três ensaios do ponto central, para avaliar as propriedades físico químicas e organolépticas dos produtos. A figura 1 mostra as formulações da bebida mista de aipim manga e mel. Os resultados das análises se são mostrados na Tabela 3.
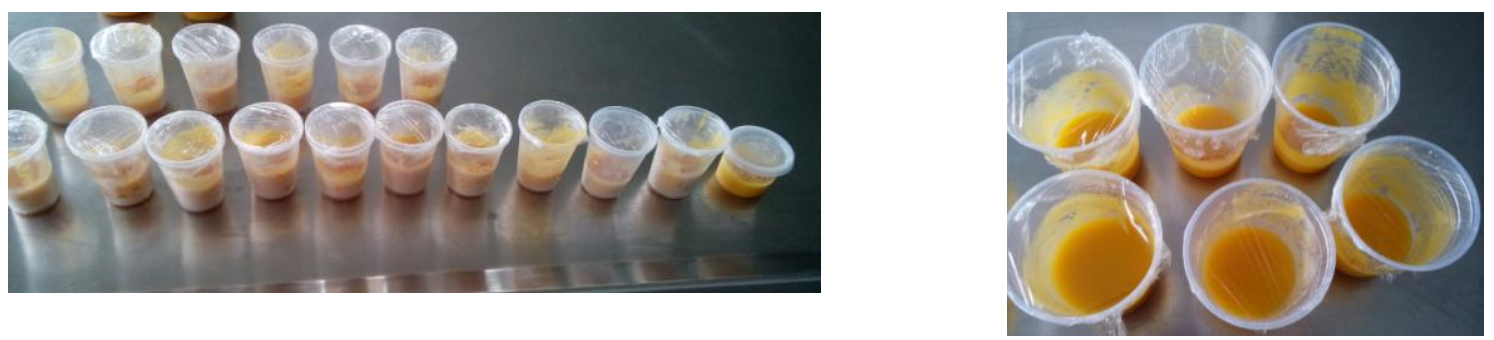

Figura 1: Formulações da bebida mista de aipim manga e mel.

Tabela 3: Caracterização físico-química das formulações do planejamento $2^{3}$ da bebida mista.

\begin{tabular}{cccccc}
\hline Formulação & $\begin{array}{c}\text { Sólidos solúveis } \\
\left({ }^{\circ} \mathbf{B r i x}\right)\end{array}$ & pH & $\begin{array}{c}\text { Acidez (Ácido } \\
\text { cítrico, \%) }\end{array}$ & $\begin{array}{c}\text { Vitamina C } \\
(\mathbf{m g} / \mathbf{1 0 0 g})\end{array}$ & $\begin{array}{c}\text { Açúcares } \\
\text { Totais } \\
(\mathbf{g} 100 g)\end{array}$ \\
\hline 1 & $10,30 \pm 0,10$ & $3,99 \pm 0,01$ & $0,25 \pm 0,01$ & $3,44 \pm 0,14$ & $9,61 \pm 1,08$ \\
2 & $9,30 \pm 0,10$ & $4,09 \pm 0,01$ & $0,23 \pm 0,01$ & $3,61 \pm 0,17$ & $14,14 \pm 0,06$ \\
\hline
\end{tabular}




\begin{tabular}{cccccc}
\hline 3 & $10,00 \pm 0,10$ & $3,92 \pm 0,01$ & $0,31 \pm 0,02$ & $4,98 \pm 0,01$ & $4,09 \pm 0,02$ \\
4 & $10,30 \pm 0,10$ & $4,08 \pm 0,01$ & $0,28 \pm 0,02$ & $4,56 \pm 0,12$ & $4,17 \pm 0,81$ \\
5 & $17,00 \pm 0,10$ & $3,98 \pm 0,01$ & $0,23 \pm 0,01$ & $3,83 \pm 0,04$ & $20,34 \pm 1,54$ \\
6 & $15,60 \pm 0,10$ & $4,02 \pm 0,01$ & $0,26 \pm 0,02$ & $5,08 \pm 0,18$ & $14,71 \pm 0,16$ \\
7 & $16,60 \pm 0,10$ & $3,95 \pm 0,01$ & $0,28 \pm 0,01$ & $4,16 \pm 0,21$ & $13,68 \pm 0,67$ \\
8 & $15,50 \pm 0,10$ & $4,07 \pm 0,01$ & $0,26 \pm 0,01$ & $4,63 \pm 0,01$ & 16,23 \\
9 & $12,40 \pm 0,10$ & $4,00 \pm 0,01$ & $0,26 \pm 0,01$ & $4,08 \pm 0,03$ & $12,30 \pm 0,38$ \\
10 & $12,40 \pm 0,10$ & $4,00 \pm 0,01$ & $0,26 \pm 0,02$ & $4,32 \pm 0,14$ & $15,76 \pm 0,91$ \\
11 & $12,30 \pm 0,10$ & $3,95 \pm 0,01$ & $0,28 \pm 0,01$ & $4,81 \pm 0,01$ & $9,580,62$ \\
\hline
\end{tabular}

As amostras de modo geral apresentaram características favoráveis de ${ }^{\circ} \mathrm{Brix}, \mathrm{pH}$, Acidez e Açúcares totais. O teor de vitamina c em ambas as amostras foram baixos. A vitamina $\mathrm{C}$ é muito sensível à luz, à temperatura e ao oxigênio do ar, (AS PROPRIEDADES, 2016), assim as condições de processamento e armazenamento desde a matéria prima até a obtenção da bebida e posterior realização da análise, pode ter ocasionado a perda deste nutriente. A homogeneidade da bebida mista foi um resultado positivo, pois mesmo após 3 dias de preparo não foi observada a separação de fases, muito comum nos sucos consumidos usualmente. A Coloração o odor da bebida foram realçados com a presença do mel.

Para avaliar a estabilidade da bebida mista a mesma foi mantida sob refrigeração por 15 dias e verificado o $\mathrm{pH}$ e o ${ }^{\circ} \mathrm{Brix}$, no dia 1 , dia 3 e dia 15 . Os resultados do planejamento $2^{3}$ são mostrados na tabela 4 .

Tabela 4: Variação dos dados de $\mathrm{pH}$ e ${ }^{\circ}$ Brix das formulações do planejamento $2^{3}$ sobre refrigeração.

\begin{tabular}{ccccccc}
\hline & \multicolumn{2}{c}{ Dia 1 } & \multicolumn{2}{c}{ Dia 3 } & \multicolumn{2}{c}{ Dia 15 } \\
\cline { 2 - 7 } Formulação & $\begin{array}{c}\text { Sólidos } \\
\text { solúveis } \\
\left({ }^{\circ} \text { Brix }\right)\end{array}$ & $\mathbf{p H}$ & $\begin{array}{c}\text { Sólidos } \\
\text { solúveis } \\
\left({ }^{\circ} \text { Brix }\right)\end{array}$ & pH & $\begin{array}{c}\text { Sólidos } \\
\left.\text { solúveis ( }{ }^{\circ} \text { Brix }\right)\end{array}$ & pH \\
\hline 1 & $10,30 \pm 0,10$ & $3,99 \pm 0,01$ & $10,20 \pm 0,10$ & $3,97 \pm 0,01$ & $4,70 \pm 0,10$ & $3,70 \pm 0,01$ \\
2 & $9,30 \pm 0,10$ & $4,09 \pm 0,01$ & $9,20 \pm 0,10$ & $4,08 \pm 0,01$ & $4,50 \pm 0,10$ & $3,75 \pm 0,01$ \\
3 & $10,00 \pm 0,10$ & $3,92 \pm 0,01$ & $9,80 \pm 0,10$ & $3,90 \pm 0,01$ & $5,40 \pm 0,10$ & $3,69 \pm 0,01$ \\
4 & $10,30 \pm 0,10$ & $4,08 \pm 0,01$ & $10,00 \pm 0,10$ & $4,05 \pm 0,01$ & $5,30 \pm 0,10$ & $3,76 \pm 0,01$ \\
5 & $17,00 \pm 0,10$ & $3,98 \pm 0,01$ & $17,00 \pm 0,10$ & $3,98 \pm 0,01$ & $14,00 \pm 0,10$ & $3,69 \pm 0,01$ \\
6 & $15,60 \pm 0,10$ & $4,02 \pm 0,01$ & $15,50 \pm 0,10$ & $4,02 \pm 0,01$ & $12,30 \pm 0,10$ & $3,74 \pm 0,01$ \\
7 & $16,60 \pm 0,10$ & $3,95 \pm 0,01$ & $16,60 \pm 0,10$ & $3,95 \pm 0,01$ & $12,00 \pm 0,10$ & $3,65 \pm 0,01$ \\
8 & $15,50 \pm 0,10$ & $4,07 \pm 0,01$ & $15,50 \pm 0,10$ & $4,07 \pm 0,01$ & $11,60 \pm 0,10$ & $3,75 \pm 0,01$ \\
9 & $12,40 \pm 0,10$ & $4,00 \pm 0,01$ & $12,30 \pm 0,10$ & $3,95 \pm 0,01$ & $9,70 \pm 0,10$ & $3,73 \pm 0,01$ \\
10 & $12,40 \pm 0,10$ & $4,00 \pm 0,01$ & $12,30 \pm 0,10$ & $3,95 \pm 0,01$ & $10,00 \pm 0,10$ & $3,79 \pm 0,01$ \\
11 & $12,30 \pm 0,10$ & $3,95 \pm 0,01$ & $12,20 \pm 0,10$ & $3,93 \pm 0,01$ & $8,40 \pm 0,10$ & $3,68 \pm 0,01$ \\
\hline
\end{tabular}


Foi verificado que a bebida é estável sob condições de armazenamento e refrigeração adequadas por 3 dias, pois as análises de $\mathrm{pH}$ e ${ }^{\circ}$ Brix não teve variação significativa. Por outro lado as análises de $\mathrm{pH}$ e ${ }^{\circ}$ Brix do dia 15 , variaram significativamente.

\section{CONSIDERAÇÕES FINAIS (ou Conclusão)}

As análises físico-químicas das amostras de manga e aipim estão de acordo com a legislação. As amostras de modo geral apresentaram características favoráveis de ${ }^{\circ}$ Brix, pH, Acidez e Açúcares totais. E baixo teor de vitamina c em ambas as amostras foram baixos. A homogeneidade da bebida mista foi um resultado positivo, pois mesmo após 3 dias de preparo não foi observada a separação de fases. A bebida é estável sob condições de armazenamento e refrigeração adequadas por 3 dias.

\section{REFERÊNCIAS}

ABREU, D. A., et al, Desenvolvimento de bebidas mistas à base de manga, maracujá e caju adicionadas de prebióticos. Alimentos e Nutrição, Araraquara, v. 22, n. 2, p. 197-203, abr./jun. 2011.

AS PROPRIEDADES funcionais da vitamina C, Aditivos e ingredientes, 2016. Disponível em:

$\langle\underline{\text { http://funcionaisnutraceuticos.com.br/upload_arquivos/201607/201607013443400146 }}$ 9726704.pdf $>$

DUBOIS, M. K. A.; GILLES, J.K.; HAMILTON, P.A., Colorimetric method for determination of sugars and related substances. Analytical Chemistry, v.28, 1956, p.350-356.

FERREIRA, C. F., et al. Caracterização dos méis de Apismelífera de diferentes floradas comparado com méis de abelhas indígenas Meliponeae. In: Encontro Nacional de Educação, Ciência e Tecnologia/ UEPB, 2012. Anais... Campina Grande-PB: Universidade Estadual da Paraíba. Disponível:

em<http://www.editorarealize.com.br/revistas/enect/trabalhos/Poster_163.pdf $>$. Acesso em: 30 de Jul. de 2017.

FILHO J. R. F., et al. Cultivo, processamento e uso da mandioca: Instruções práticas. Embrapa, Brasília, 2013.

GRANJA et al, Avaliação do potencial antioxidante da casca de manga em espetinho de tilápia do Nilo (Oreochromis niloticus), Evolvere Science, V. 3, n. 1, 2014

INSTITUTO ADOLFO LUTZ (IAL). Métodos físico-químicos para análise de alimentos, 4 ed. São Paulo, Instituto Adolfo Lutz, 2008.

IURLINA, M. O., FRITZ, R., 2005. Characterization of microorganisms in Argentinean honeys from different sources. International Journal of Food Microbiology, 105, 297-304.

MALDONADE, I. R.; CARVALHO, P. G. B.; FERREIRA, N. A. F.; MOULIN, B. S. F., Protocolo para determinação de açúcares redutores pelo método de Somogyi-Nelson, Embrapa, Mar. 2013. Disponível em: <http://www.cnph.embrapa.br/paginas/serie_documentos/publicacoes2013/cot_86.pdf>. Acesso em: 10 nov. 2016.

SANTOS, J. C. R.; SOUZA, S. M. A.; MARTINEZ, E. A., Caracterização Físico-Química da Polpa de Manga e de Aipim para Utilização Na Produção de Bebida Mista, Higiene Alimentar, v. 31, Fortaleza, 2017. 
SERRA M. C. C., As Propriedades Antioxidantes do Mel, Centro de Estudos de Engenharia Química, Instituto Superior de Engenharia de Lisboa, 201_. Disponível em: <http://www.oapicultor.com/artigos/Propriedades\%20anti\%20Oxidante.pdf>.

Acesso em: 128 de mar. de 2016.

SILVA, P. C. G.; CORREIA R. C., Cultivo da Mangueira, Embrapa, Semiárido Sistemas de Produção 2, 2004. Disponível em:

$<$ https://sistemasdeproducao.cnptia.embrapa.br/FontesHTML/Manga/CultivodaMangue ira/socioeconomia.htm>. Acesso em: 12 de dez. de 2015. 